\title{
FORMULATION, CHARACTERIZATION AND STABILITY STUDY OF FAST DISSOLVING THIN FILM CONTAINING ASTAXANTHIN NANOEMULSION USING HYDROXYPROPYLMETHYL CELLULOSE POLYMER
}

\author{
LUSI NURDIANTI ${ }^{1,2}$, IYAN SOPYAN ${ }^{1}$, TAOFIK RUSDIANA ${ }^{1^{*}}$
}

1Department of Pharmaceutics and Pharmaceutical Technology, Faculty of Pharmacy, Padjadjaran University, Bandung, Indonesia, 2Department of Pharmacy, Bakti Tunas Husada Institute of Health Science, Tasikmalaya, Indonesia

Email: t.rusdiana@unpad.ac.id

Received: 20 Aug 2020, Revised and Accepted: 05 Oct 2020

\begin{abstract}
Objective: The present study was conducted to formulate and characterize the thin film containing astaxanthin nanoemulsion (TF-ASN) using Hydroxypropylmethyl Cellulose (HPMC) polymer as a film matrix system. The stability studies in different storage conditions were also performed.

Methods: Astaxanthin nanoemulsion (As-NE) was prepared by using self-nanoemulsifying method, followed by incorporation into the HPMC matrix system by solvent casting method to forming TF-ASN. Evaluation of TF-ASN was performed by physical and mechanical characterizations. Stability study was carried out in both of accelerated (temperature of $40 \pm 2{ }^{\circ} \mathrm{C} / 75 \pm 5 \% \mathrm{RH}$ ) and non-accelerated (at ambient temperature) conditions. Assay of astaxanthin in individual TF-ASN was determined compared to pure astaxanthin.
\end{abstract}

Results: TF-ASN had good physical and mechanical characteristics that suitable for intraoral administration.

Conclusion: For the study of stability under different storage conditions, it was proven that nanoemulsion form was packed in a HPMC matrix could enhance the stability of the astaxanthin.

Keywords: Astaxanthin, Nanoemulsion, Thin film, Solvent casting method

(C) 2021 The Authors. Published by Innovare Academic Sciences Pvt Ltd. Thisis an open access article under theCC BYlicense (https://creativecommons.org/licenses/by/4.0/) DOI: https://dx.doi.org/10.22159/ijap.2021.v13s3.03 Journal homepage: https://innovareacademics.in/journals/index.php/ijap

\section{INTRODUCTION}

Carotenoids are associated with a number of health benefits, and epidemiological studies show an inverse relationship between cardiovascular disease and cancer that occurs with the habit of consuming high amounts of carotenoids contained in foods, such as fruits and vegetables. The biological mechanism of carotenoids is still unclear, but apart from provitamin-A activity, carotenoids show antioxidant characteristics that can affect cell growth regulation, and modulate gene expression and immune response [1, 2]. Astaxanthin is one of the natural carotenoids with strong antioxidant characteristics (super-antioxidant), has no activity like a vitamin A and is a group of xanthophyll. Astaxanthin is a fat-soluble pigment synthesized by plants and some types of algae $[3,4]$.

To understand better the potential benefits of high consumption of carotenoids in food, or as food supplements, there are recent studies regarding the absorption, distribution, and metabolism of various types of carotenoids in human subjects [5]. The bioavailability of some carotenoids, which are highly lipophilic, is low. The value varies from less than $10 \%$ of raw vegetables to more than $50 \%$ in oil-containing preparations. Limitation in terms of dissolution in the gastrointestinal fluid is one of the causes of low bioavailability. Another factor that causes the limitation of absorption of these compounds is the saturation of carotenoids to enter into micelles formed by bile in the gastrointestinal tract at high doses [6]. Increased bioavailability of carotenoids after administration together with fat is due to the conjugation of carotenoids into micelles of the bile salt. Factor that causes low astaxanthin bioavailability is due to the degradation of astaxanthin in the gastrointestinal tract and the possibility of astaxanthin experiencing first pass metabolism. A study of pharmacokinetics and the presence of a mechanism of degradation via first pass metabolism were carried out by Choi et al., which stated that the hepatic and gastrointestinal astaxanthin elimination extraction ratio were 0.490 and 0.901 , respectively [7]. The value of the elimination extraction ratio ranges between 0 and 1 where the ratio value closes to 1 indicates that the drug is eliminated by the intended organ.
The film dosage form is chosen to deliver the intraoral small dose of active substances because: a) has a relatively larger surface area than the tablet so that it is easier to wet and finally the disintegration and dissolution process of the film will be faster, b) more flexible so that it is not easily fragile and brittle like tablets when transportation, handling, until storage by patients becomes easier [8], and (c) with the use of mucoadhesive materials will increase the contact time so that the time for absorption of active substances increases [9].

In increasing stability and absorption of astaxanthin, encapsulation of astaxanthin was carried out in a nanometer-sized lipid carrier system. With this form, astaxanthin will be protected from degrading enzyme conditions and allow increasing transcellular (intracellular, passing through cells) absorption in particles less than 50-100 $\mathrm{nm}$ and paracellular (intercellular, passing through the edge of the cell). Generally, high molecular weight active substances are absorbed via the transcellular route. Hydrophilic molecules will pass the paracellular route while lipophilic molecules will pass through the transcellular route $[10,11]$. This nanometer-sized carrier system will be developed using the Self-Nanoemulsifying Drug Delivery System (SNEDDS) method. Through this method, the nanocarrier-forming material will spontaneously produce a nanometer-sized globule if the material is dispersed in the appropriate conditions. After that, As-NE was packaged into the thin film dosage form by using HPMC polymer with the target for delivery of astaxanthin via intraoral route. With this strategy, our hypothesis is the stability and bioavailability of astaxanthin can be increased. This research is part of a series of studies that use natural polymers as film-making polymers. Differences in types and concentrations of polymers will affect the film mechanical properties. Previous study, we have conducted a comparative study that investigates the effect of natural polymers sodium alginate and gelatin on the film characteristics.

This research was intended to develop a new astaxanthin delivery system to optimize the astaxanthin therapy. This research is a further research on the development of As-NE that has been successfully developed in previous study [12]. In this study, As-NE was prepared by using self nanoemulsifying method, where thin film 
was prepared by using solvent casting method with combination between polymer and plasticizer. Both physical and mechanical evaluations of TF-ASN were performed including film organoleptic, film thickness, folding resistance, weight uniformity, film disintegration time, tensile strength, percent elongation, and film morphology. At the end of the study, the effectiveness of the dosage form in protecting the stability of astaxanthin was proven by the stability test compared to pure astaxanthin.

\section{MATERIALS AND METHODS}

\section{Materials}

Astaxanthin (Astareal ${ }^{\circledR}$ L10) was purchased from Fuji Chemical Industries (Japan). Sunflower oil was purchased from Jan Dekker International (Netherland). Polyoxy-35-castor oil (Kolliphor ${ }^{\circledR}$ RH40) was purchased from BASF (Indonesia). Polyethylene Glycol 400 (PEG 400) was purchased from Merck (Indonesia). Hydroxypropylmethyl cellulose (Pharmacoat ${ }^{\circledR} 606$ ) was purchased from Shinetsu Chemical, Co., LTD (Japan). Poly (butyl methacrylate, (2-dimethylaminoethyl) methacrylate, methyl methacrylate) 1:2:1 (Eudragit ${ }^{\circledR}$ E PO) was purchased from Evonik Industries (Thailand). All other chemicals used were of pharmaceutical grade.

\section{Methods \\ Preparation of As-NE}

Four milligram astaxanthin was dissolved in 1 gram of oil phase containing sunflower oil, kolliphor ${ }^{\circledR}$ RH40, and PEG 400 with the ratio of 1:8:1, respectively. Then, the mixture was mixed for $30 \mathrm{~min}$ using magnetic stirrer (IKA ${ }^{\circledR}$ C-MAG HS7), followed by sonication for $1 \mathrm{~h}$ (Krisbow $\left.{ }^{\circledR}\right)$. Nanoemulsion will be formed after addition deionized water until 20 gram of solution.

\section{Optimization of thin film preparation}

In this study, HPMC was used as thin film forming polymers, with PEG 400 as plasticizer. Design of experiment for optimization both of polymers and plasticizer concentrations that were able to produce the best thin layer preparation were carried out by using Design-Expert ${ }^{\circledR}$ Version 12 Software with Simple Lattice Design method. Thin film was formed by pouring wet mixture into the flat and clean surface petri dish in diameter of $10 \mathrm{~cm}$ and dried for $48 \mathrm{~h}$ at ambient temperature. After dried, film thickness and film disintegration time were evaluated. The designs of experimental from the software are given in table 1.

Table 1: Experimental designs of thin film preparation

\begin{tabular}{|c|c|c|c|}
\hline \multirow[t]{2}{*}{ Formula } & \multicolumn{3}{|c|}{ Components (\%, w/v) } \\
\hline & HPMC & PEG 400 & Deionized water \\
\hline F1 & 2.70 & 1.00 & Adjust to $100 \%$ \\
\hline $\mathrm{F} 2$ & 2.70 & 1.00 & \\
\hline F3 & 8.00 & 0.11 & \\
\hline $\mathrm{F} 4$ & 4.03 & 0.78 & \\
\hline F5 & 5.35 & 0.55 & \\
\hline F6 & 5.35 & 0.55 & \\
\hline F7 & 8.00 & 0.11 & \\
\hline F8 & 6.67 & 0.33 & \\
\hline
\end{tabular}

\section{Preparation of TF-ASN}

As-NE containing $0.02 \%(\mathrm{w} / \mathrm{w})$ of astaxanthin was added slowly into the mixture of optimized polymers matrix system according to table 1 and $0.04 \%\left(\mathrm{w} / \mathrm{v}\right.$ ) of Eudragit ${ }^{\circledR}$ E PO (in $10 \%$ (v/v) of Ethanol $96 \%$ ). The final mixing was done by using magnetic stirrer (IKA ${ }^{\circledR}$ CMAG HS7) in $100 \mathrm{rpm}$ for 1 hour. Thin film was formed by pouring wet mixture into the flat and clean surface petri dish in diameter of $10 \mathrm{~cm}$ and dried for $48 \mathrm{~h}$ at ambient temperature. Then, the TF-ASN was cut into the size of $3 \times 3 \mathrm{~cm}^{2}$.

\section{Physical and mechanical characterizations of TF-ASN}

\section{Organoleptic, film thickness and weight uniformity}

Organoleptic including color, odor, and clarity of thin film was visually observed. Film thickness was carried out by using micrometer (Mitutoyo ${ }^{\circledR}$ ) at three different locations on the film. Meanwhile, weight uniformity of thin film was determined by weighing 6 pieces of thin film (with size of $3 \times 3 \mathrm{~cm}^{2}$ ) using analytical balance (Mettler Toledo XS204). It is important to know these parameters because directly related to the accuracy of doses in the film.

\section{Folding resistance of TF-ASN}

Folding resistance of TF-ASN was determined by repeated folding of the film at the same place till the film breaks. The number of time the film is folded without breaking is computed as the folding resistance value [8].

\section{Film disintegration time}

Film disintegration time was determined visually in a petri dish containing $10 \mathrm{ml}$ of phosphate buffer $\mathrm{pH} 6.8$ at $37^{\circ} \mathrm{C}$ where the container was shaken in every $10 \mathrm{~s}$. Disintegration time is the time at which the film begins to break or collapse. The disintegration time of a good thin film is less than $60 \mathrm{~s}$ [13].

\section{Mechanical stress tests: tensile strength and percent elongation}

Mechanical stress tests of TF-ASN were performed by using Universal testing machine (Oriented UCT-5T). Dry film was cut into uniform sized pieces using sharp bladed cutting mold. Film (with area exposed to stress of $25 \mathrm{~mm} \times 4 \mathrm{~mm}$ ) was sandwiched between two machine jaws. Load was given to the film gradually (at a speed of $30 \mathrm{~mm} /$ minute) and automatically until the film shredded. Test was carried out at $23{ }^{\circ} \mathrm{C}$ and $50 \%$ relative humidity. Tensile strength is calculated by the applied load at rupture divided by the crosssectional area of the film. Percent elongation is defined as strain of the film. Strain is basically the deformation of strip divided by original dimension of the sample.

\section{Film morphology}

Film morphology of TF-ASN was examined by Scanning Electron Microscopy (SEM). Sample was sized according to the specimen container, followed by smearing with silver paste at several points before the sample was placed. Sample was dried at $20^{\circ} \mathrm{C}$. The sample was putted into the fine coat in voltage condition of $1.2 \mathrm{kV}$, ampere of 6-7.5 mA, and air pressure of 0.2 torr for 4 min to obtain a sample with a thickness about $400 \AA$.

\section{Stability study of TF-ASN}

Accelerated stability study was performed by refers to the ICH Q1A Guideline [14]. TF-ASN was packed into the glass bottle and then stored at ambient temperature and in the climatic chamber with temperature of $40 \pm 2{ }^{\circ} \mathrm{C} / 75 \pm 5 \% \mathrm{RH}$ for 6 mo at intervals of $0 ; 0.25$; $0.5 ; 0.75 ; 1 ; 2 ; 3$; and 6 mo. Assay of astaxanthin were determined by dissolving TF-ASN (with size of $3 \times 3 \mathrm{~cm}^{2}$ ) in volumetric flask containing $10 \mathrm{ml}$ of phosphate buffer $\mathrm{pH} 6.8$ for $30 \mathrm{~min}$. Then, the absorbance was measured by UV-Visible Spectrophotometer (Genesys $^{\mathrm{TM}} 10 \mathrm{~S}$ ) at the maximum wavelength of $472 \mathrm{~nm}$. Assay of astaxanthin in TF-ASN was calculated by estimating the astaxanthin content in individual film. 


\section{RESULTS AND DISCUSSION}

Self-nanoemulsifying dosage forms are anhydrous homogenous liquid mixtures consisting of oil, surfactant, drug, and co-surfactant, which spontaneously form oil-in-water nanoemulsion upon dilution with water under gentle stirring $[15,16]$. The illustration of As-NE structure was described in fig. 1 below. Adding surfactant and cosurfactant into systems enhances drug dissolution and formulation dispersibility during dilution with aqueous medium of GIT. During dilution with water, active substance dissolves in oil phase and/or surfactant, which forms a film between oil and water phase [15]. The appropriate type and ratio of oil phase, surfactant and co-surfactant are critical parameters in formation of nanoemulsion. Based on our previous study, the best ratio between sunflower oil as oil phase, Kolliphor ${ }^{\circledR}$ RH40 as surfactant, and PEG 400 as co-surfactant were 1:8:1, respectively. As-NE had droplets size in the nano-range (10-20 $\mathrm{nm}$ ) with polydispersity index was less than 0.5 , while zeta potential value was more than- $20 \mathrm{mV}$ [12].

In the preliminary study, before formulation of the astaxanthin nanoemulsion into the polymer matrix system, optimization of polymer and plasticizer concentrations were carried out by using Design-Expert ${ }^{\circledR}$ Version 12 Software with Simple Lattice Design method. This software is a tool to find out the optimal variations between polymer and plasticizer concentrations in thin film preparation. The software will produce 8 experimental designs. Critical evaluations including film disintegration time and film thickness were carried out to find the best thin film characteristics. These parameters were simple parameters that related to the quality of the film and can be quantified. The results of evaluation in the preliminary study of thin film matrix system are given in table 2. The best characteristic of thin film was determined by using Simplex Lattice Design Modeling. The results of data analysis from the model are presented in fig. 2 .

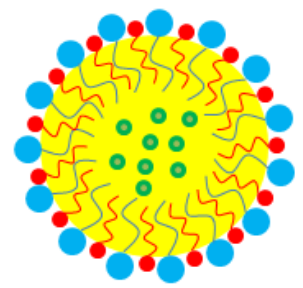

8) Astaxanthin Oil Phase $\bigcirc$ Surfactant $\sim$ co-surfactant

Fig. 1: The illustration of As-NE structure

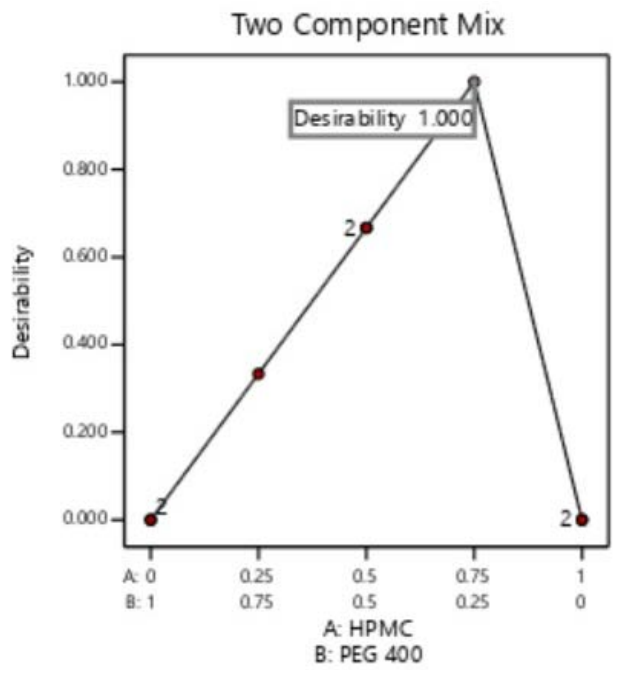

[A]

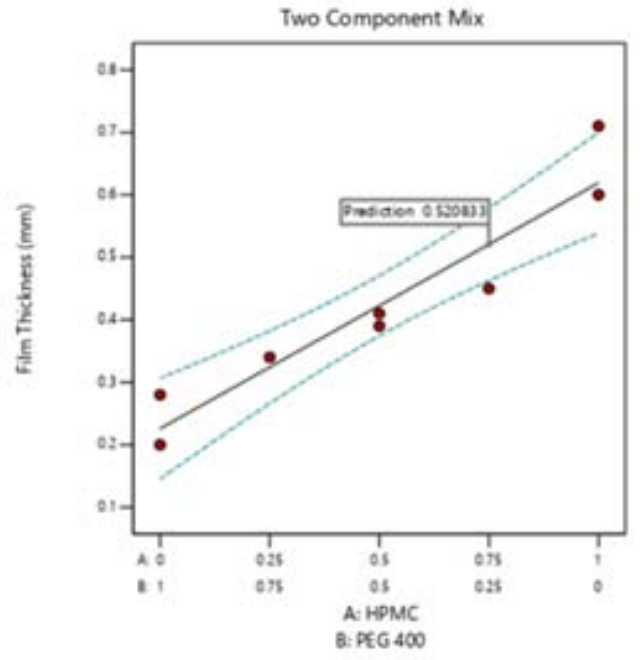

[B]

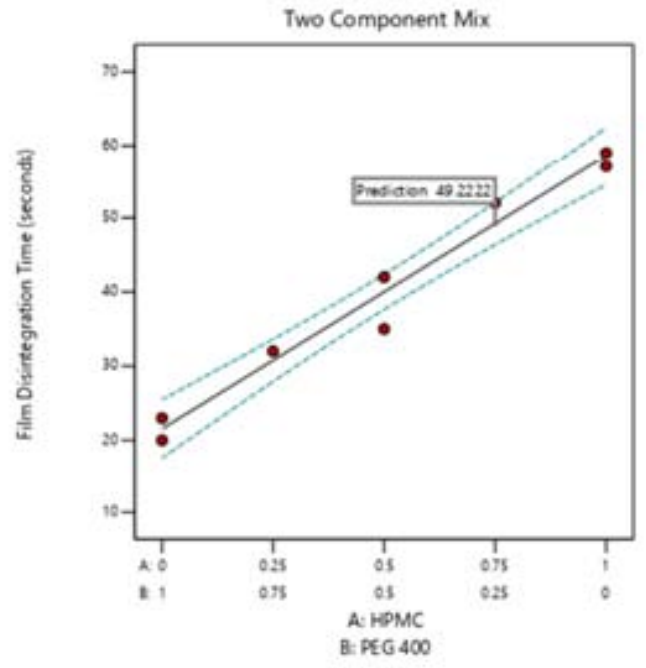

[C]

Fig. 2: Data analysis of thin film optimization using Simplex Lattice Design modeling. [A]: Desirability value; [B]: Film thickness prediction value; [C]: Film disintegration time prediction value 
Table 2: The results of preliminary study on optimization of polymer matrix system

\begin{tabular}{|c|c|c|c|c|}
\hline Parameters & Formula & & & \\
\hline \multirow{4}{*}{ Film thickness (mm) } & F1 & F2 & F3 & F4 \\
\hline & $0.32 \pm 0.002$ & $0.33 \pm 0.002$ & $0.58 \pm 0.003$ & $0.38 \pm 0.001$ \\
\hline & F5 & F6 & F7 & F8 \\
\hline & $0.40 \pm 0.002$ & $0.42 \pm 0.002$ & $0.56 \pm 0.002$ & $0.48 \pm 0.001$ \\
\hline \multirow[t]{4}{*}{ Film disintegration time (s) } & F1 & F2 & F3 & $\mathrm{F} 4$ \\
\hline & $64.83 \pm 0.55$ & $66.27 \pm 0.56$ & $62.10 \pm 0.50$ & $64.10 \pm 0.28$ \\
\hline & F5 & F6 & F7 & F8 \\
\hline & $63.53 \pm 0.30$ & $63.43 \pm 0.35$ & $64.63 \pm 0.28$ & $48.43 \pm 0.35$ \\
\hline
\end{tabular}

*) Values are given as the mean \pm standard deviation $(n=3)$.

Based on the contour plots in fig. 2, it can be seen that effects of concentration polymer and plasticizer. The higher of polymer concentration, the longer of the film disintegration time needed, as well as the increasing of film thickness. Contrary to the effects of PEG on film thickness and disintegration time, where the higher of PEG concentration, the thinner of the film produced and the faster of the film disintegrated. The concentration of polymer is important factor in development of thin film. The integrity of fast dissolving oral film is dependent upon selection of polymer nature and its concentration. Different polymers are employed to modulate diverse properties of films $[17,18]$. Polyethylene glycol (PEG) also has a good film forming properties either alone or in combination with other polymers [19]. The disintegration rate of the polymer is decreased by increasing the molecular weight and its concentration of polymer film matrix system $[20,21]$. In thin film development, mechanical properties such as tensile strength and percent elongation are improved by adding plasticizer to the formulations [20]. Mechanical property of thin film is plasticizer concentration dependent [21]. The proper selection of the plasticizer is very important. The improper selection may cause cracking and splitting of the film $[20,22]$.

From the desirability value (1.000) in fig. 2A confirmed that mixture of HPMC and PEG 400 with film thickness around of $0.520833 \mathrm{~mm}$ and film disintegration time around of $49.2222 \mathrm{~s}$ was chosen for the next trial. Desirability value is the value from zero (outside of the limits) to one (at the goal). Desirability is simply a mathematical method to find the optimum (closed to one) [23]. So, it can be concluded that for the mixture contains of $6.67 \%(\mathrm{w} / \mathrm{v})$ HPMC with $0.33 \%(\mathrm{w} / \mathrm{v}$ ) PEG 400 (F8) was the best combination polymer matrix system for preparation of TF-ASN.

Table 3: Physical and mechanical properties of TF-ASN

\begin{tabular}{ll}
\hline Parameters & Observation/Results \\
\hline Film organoleptic & Orange, clear, and odorless \\
Film thickness (mm)* & $0.45 \pm 0.02$ \\
Folding resistance (times) & $>300$ \\
Weight Uniformity/sheet $3 \times 3 \mathrm{~cm}(\mathrm{mg})^{*}$ & $203.4 \pm 0.2$ \\
Film disintegration time (s)* & $59.67 \pm 1.5$ \\
Tensile strength (MPa) & $7.13 \pm 1.31$ \\
Percent elongation (\%)* & $5.53 \pm 1.64$ \\
\hline
\end{tabular}

*Values are given as mean \pm standard deviation $(n=3)$.

The film properties containing astaxanthin nanoemulsion prepared by using F8 are presented in table 3. In this study, films prepared using $10 \mathrm{~mm}$ petri dish in diameter showed good weight homogeneity. Folding resistance of all films were more than 300 times, which indicates that the film had good flexibility. All films showed the disintegration time around $60 \mathrm{~s}$, which related to easily of drugs released from the matrix system [13]. The weight variation is generally determined to ensure that each film contains the consistent amount of a drug without significant deviation. A large variation in weight signifies the inefficiency of the method applied and high chances are there for non-uniformity in drug content [24].

The intraoral film must be flexible, soft, elastic, but must be strong enough against stress condition in the oral cavity [18, 25]. Mechanical properties of films can be defined in terms of percent elongations and tensile strength [26, 27]. It has been known that soft and weak polymers exhibit low tensile strength and low elongation at break; whereas the hard and tough polymer has a high tensile strength and high elongation at break [28]. The concentration and types of the polymers are largely responsible for producing a film having good mechanical strength and integrity [29]. HPMC is one of the non-ionic polymers with moderate mucoadhesive properties that stable at pH 3.0 to 11.0. Generally, the concentrations of HPMC used in the film formulation are between 2-20\% [18]. Therefore, HMPC was chosen as a film-making polymer because of its stability and mucoadhesive properties.

From the results in table 3 , it was confirmed that TF-ASN was a flexible, weak, and soft film. Such characteristics are suitable for our drug delivery targeting via intraoral. With such characteristics, the thin film will be more comfortable for patient's use, especially supported by the mucoadhesive characteristic of HPMC which makes the contact time of TF-ASN with the oral mucosa become longer. Visual observation of TF-ASN was done by observing the organoleptic. TF-ASN had orange color, odorless, smooth surface and transparent (fig. 3), but based on the morphological result by SEM (fig. 4), it was found that the surface of the film had many holes, which correlate to the weak nature of film due to small tensile strength value.

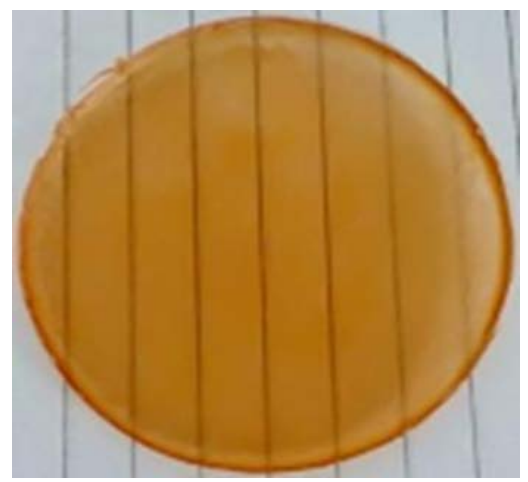

Fig. 3: The visual observation of TF-ASN 


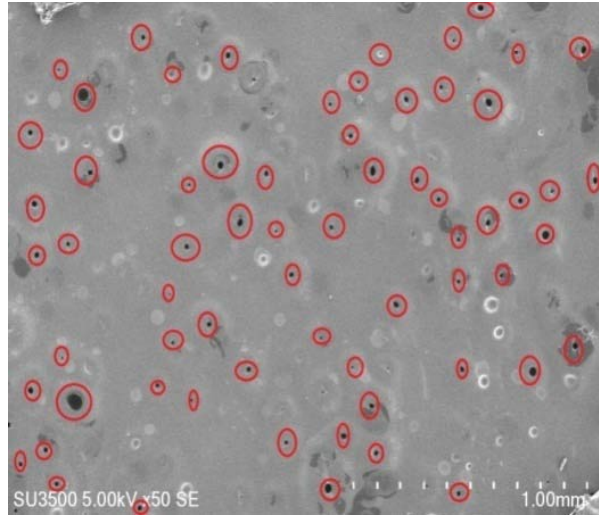

Fig. 4: The morphology of TF-ASN with magnification of 50 times. Red circle showed the holes in the film surface

As a natural antioxidant, astaxanthin can easily be degraded by thermal or oxidative processes during storage or application. Astaxanthin is a highly unsaturated molecule and thus it is highly sensitive to high temperature, light, and oxidative conditions which possesses less activity $[30,31]$. In this study, we had proven the effectiveness of our astaxanthin's carrier/dosage form through the stability testing and comparing them with stability of pure astaxanthin. Pure astaxanthin was chosen as a comparator to prove that the dosage form developed was able to increase the stability of astaxanthin.

The assay of astaxanthin in TF-ASN was measured periodically during the 6 mo of the study and the results are shown in fig. 5. The stability profile of astaxanthin in TF-ASN was however higher than those of the pure astaxanthin. This demonstrated that the nanoemulsion preparation loaded into HPMC matrix system protects the astaxanthin from thermal degradation and could potentially be used for enhancing the stability of the compounds. Stability profile of astaxanthin was also carried out under nonaccelerated storage conditions at ambient temperature during the 6 mo of the study. It is demonstrated that after 6 mo, the assay of astaxanthin in TF-ASN was also higher than that of the pure astaxanthin. The stability profiles between TF-ASN in ambient temperature compared to the accelerated condition were no different, while the pure astaxanthin stability profiles were different. It can be concluded that TF-ASN was showed a temperatureindependent protection profile. One of the advantages of nanoemulsion is improving the stability of the therapeutic agents [16]. When astaxanthin is incorporated into the nanoemulsion system, it will dissolve in the oil phase and enters to the core of micelles system, which thermodynamically stable [32]. The right combination between surfactant and co-surfactant will protect the core of the micelles from environment $[15,16]$. In addition, HPMC matrix could provide additional protective layers for the compound encapsulated and therefore resulted in the higher stability.
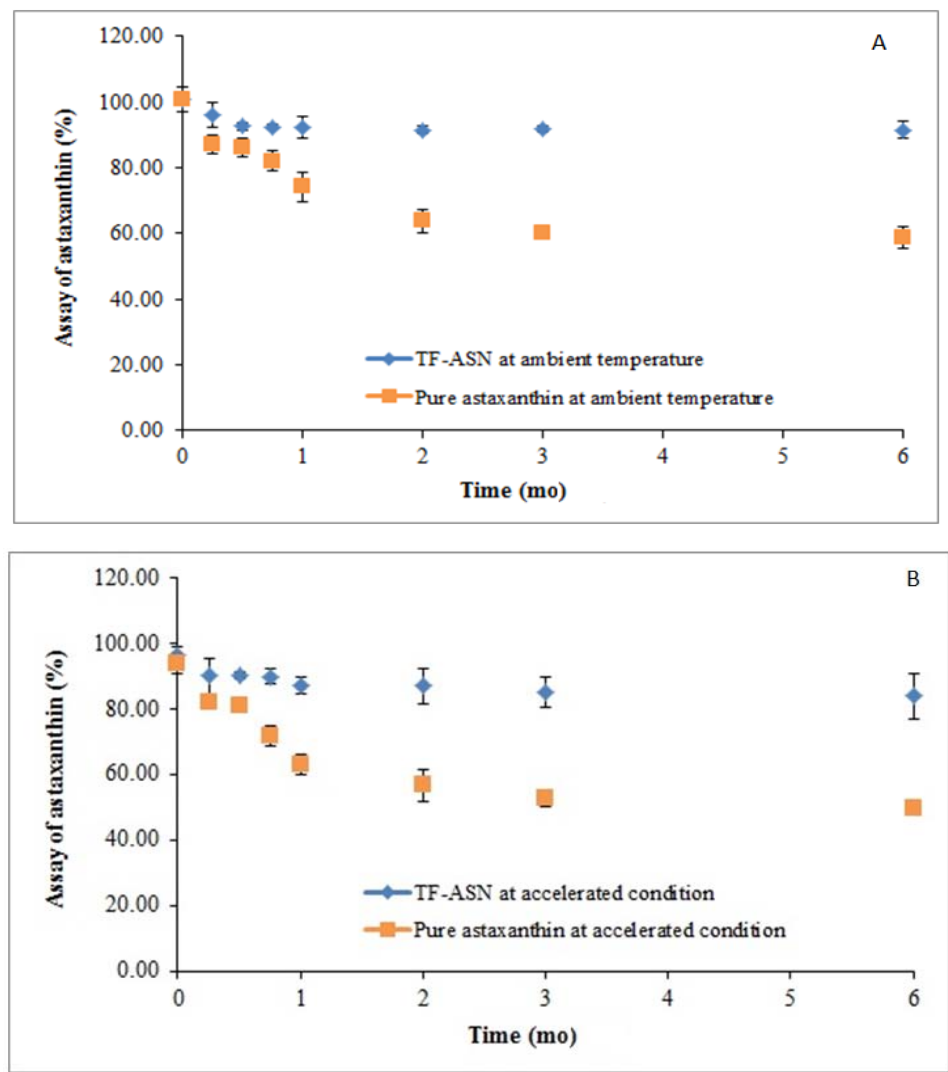

Fig. 5: Stability profile of astaxanthin in TF-ASN compared to pure astaxanthin. [A]: samples were stored at ambient temperature; [B]: samples were stored in the climatic chamber with temperature of $40 \pm 2{ }^{\circ} \mathrm{C} / 75 \pm 5 \% \mathrm{RH}$

\section{CONCLUSION}

In summary, good physical and mechanical properties of thin film containing astaxanthin nanoemulsion were successfully developed using HPMC polymer. Flexible and soft film characteristics were suitable for intraoral use. For the study of stability under different storage conditions, it was proven that nanoemulsion form was packaged in a HPMC matrix could enhance the stability of the astaxanthin.

\section{ACKNOWLEDGEMENT}

The authors gratefully acknowledge the generous grant from The Indonesian Ministry of Education Directorate General of Higher 
Education (DIKTI) that made this study possible. The authors are also thankful to the Faculty of Pharmacy, Padjadjaran University, for providing the support and their facilities.

\section{FUNDING}

Nil

\section{AUTHORS CONTRIBUTIONS}

All authors contributed equally to this manuscript.

\section{CONFLICT OF INTERESTS}

None

\section{REFERENCES}

1. Rock CL. Carotenoids: biology and treatment. Pharmacol Ther 1997;75:185-97.

2. Paiva SA, Russell RM. $\beta$-carotene and other carotenoids as antioxidants. J Am Coll Nutr 1999;18:426-33.

3. Kurashige M, Okimasu E, Inoue M, Utsumi K. Inhibition of oxidation injury of biological membranes by astaxanthin. Physiol Chem Phys Med NMR 1990;22:27-38.

4. Clark RM, Yao L, She L, Furr HC. A comparison of lycopene and astaxanthin absorption from corn oil and olive oil emulsions. Lipids 2000;35:803-6.

5. Zaripheh S, Erdman Jr JW. Factors that influence the bioavailability of xanthophylls. J Nutr 2002;132:531S-534S.

6. Parker RS. Absorption, metabolism, and transport of carotenoids. FASEB J 1996;10:542-51.

7. Choi HD, Kang HE, Yang SH, Lee MG, Shin WG. Pharmacokinetics and first-pass metabolism of astaxanthin in rats. Br J Nutr 2011;105:220-7.

8. Dixit RP, Puthli SP. Oral strip technology: overview and future potential. J Controlled Release 2009;139:94-107.

9. Mitra AK, Alur HH, Johnston P. Protein-buccal absorption, Encyclopedia of Pharmaceutical Technology; 2002. p. 2081-93.

10. Garsuch V. PhD Thesis. Preparation and characterization of fast-dissolving oral films for pediatric use. Department of Pharmaceutical Technology and Biopharmacy, Faculty of Mathematics and Natural Sciences, Heinrich Heine University Düsseldorf, Düsseldorf, Germany; 2009.

11. Chen MC, Sonaje K, Chen KJ, Sung HW. A review of the prospects for polymeric nanoparticle platforms in oral insulin delivery. Biomaterials 2011;32:9826-38.

12. Nurdianti L, Rusdiana T, Sopyan I, Putriana NA, Aiman HR, Fajria TR. Characteristics comparison of intraoral thin film containing astaxanthin nanoemulsion using sodium alginate and gelatin polymers. Turk J Pharm Sci 2020. DOI:10.4274/tjps.galenos.2020.25483

13. Nurdianti L, Aryani R, Indra I. Formulation and characterization SNE (self nanoemulsion) of astaxanthin of haematococcus pluvialis as natural super antioxidant. JSFK 2017;4:36-42.

14. Bala R, Pawar P, Khanna S, Arora S. Orally dissolving strips: a new approach to oral drug delivery system. Int J Pharm Investig 2013;3:67.
15. Guideline, IHT. Stability testing of new drug substances and products. Q1A (R2) Curr Step 2003;4:1-24.

16. Krstic M, Medarevic D, Duris J, Ibric S. Self-nanoemulsifying drug delivery systems (SNEDDS) and self-microemulsifying drug delivery systems (SMEDDS) as lipid nanocarriers for improving dissolution rate and bioavailability of poorly soluble drugs. Lipid nanocarriers for drug targeting. William Andrew Publishing; 2018. p. 473-508.

17. Date AA, Desai N, Dixit R, Nagarsenker M. Self-nanoemulsifying drug delivery systems: formulation insights, applications and advances. Nanomedicine 2010;5:1595-616.

18. Irfan M, Rabel S, Bukhtar Q, Qadir MI, Jabeen F, Khan A. Orally disintegrating films: a modern expansion in drug delivery system. Saudi Pharm J 2016;24:537-46.

19. Karki S, Kim H, Na SJ, Shin D, Jo K, Lee J. Thin films as an emerging platform for drug delivery. Asian J Pharm Sci 2016;11:559-74.

20. Pathare YS, Hastak VS, Bajaj AN. Polymers used for fast disintegrating oral films: a review. Polymer 2013;14:169-78.

21. Joshua JM, Hari R, Jyothish FK, Surendran SA. Fast dissolving oral thin films: an effective dosage form for quick releases. Drugs 2016;11:12.

22. Siddiqui MN, Garg G, Sharma PK. A short review on "A novel approach in oral fast dissolving drug delivery system and their patents". Adv Biol Res 2011;5:291-303.

23. Mandeep K, Rana AC, Nimrata S. Fast dissolving films: an innovative drug delivery system. Int J Pharm Res Allied Sci 2013;2:14-24.

24. Anderson MJ, Whitcomb PJ. Optimizing formulation performance with desirability functions. InQuebec Metallurgical Conference; 1993.

25. Nair AB, Kumria R, Harsha S, Attimarad M, Al-Dhubiab BE, Alhaider IA. In vitro techniques to evaluate buccal films. J Controlled Release 2013;166:10-21.

26. Alanazi FK, Rahman AA, Mahrous GM, Alsarra IA. Formulation and physicochemical characterisation of buccoadhesive films containing ketorolac. J Drug Delivery Sci Tech 2007;17:183-92.

27. Preis M, Knop K, Breitkreutz J. Mechanical strength test for orodispersible and buccal films. Int J Pharm 2014;461:22-9.

28. Heng PW, Chan LW, Ong KT. Influence of storage conditions and type of plasticizers on ethylcellulose and acrylate films from aqueous dispersions. J Pharm Pharm Sci 2003;6:334-44.

29. Morales JO, McConville JT. Manufacture and characterization of mucoadhesive buccal films. Eur J Pharm Biopharm 2011;77:187-99.

30. Liew KB, Tan YT, Peh KK. Effect of polymer, plasticizer and filler on orally disintegrating film. Drug Dev Ind Pharm 2014;40:110-9.

31. Ambati RR, Phang SM, Ravi S, Aswathanarayana RG. Astaxanthin: sources, extraction, stability, biological activities and its commercial applications-a review. Marine Drugs 2014;12:128-52.

32. Higuera Ciapara I, Felix Valenzuela L, Goycoolea FM, Arguelles Monal W. Microencapsulation of astaxanthin in a chitosan matrix. Carbohydr Polym 2004;56:41-45.

33. Rao SV, Shao J. Self-nanoemulsifying drug delivery systems (SNEDDS) for oral delivery of protein drugs: I. Formulation development. Int J Pharm 2008;362:2-9. 